\title{
A CASE OF EPITHELIOMA OF THE MEIBOMIAN GLANDS
}

\author{
BY
Dr. Dumitru lazarescu, Eugenia Lazarescu and EUGENE IONESCU
IASSY, ROUMANIA \\ FROM THE OPHTHALMOLOGICAL CLINIC AT IASSY : \\ DIRECTOR, PROFESSOR DR. ELENA PUSCARIU
}

Statistical research in the records of the Ophthalmological Clinic of Iassy shows that during thirteen years, from 1916 to 1930, with the exception of the year 1917 when the clinic was transformed into a war hospital, there were present 69 cases of cancer of the visual apparatus. The total number of beds available in the ophthalmological clinic has been 32 .

During the years 1919 to 1929 , inclusive, the number of cases of cancer in the region of the eye, was 53, which, in a total number of 22,288 consultations, represents an average of 0.238 per cent., and on a total of 4,866 in-patients, an average of 1.08 per cent.

Of the 53 cases of cancer of the visual apparatus, 25 were localized on the lids, representing an average of $47 \cdot 16$ per cent.

Among these cases only one neoplasm was found developed in the Meibomian glands, which demonstrates the rarity of cancer of the Meibomian glands. Morax, in 1926, when publishing his work " Cancer de l'appareil visuel," surveyed the literature and found 28 of these cases recorded, to which must be added those published recently by Glavan (Med. Sanitary Rev. 1926), and by Shoji (Arch.d Ophthal. 1929). Shoji gave references to cases by Komoto (1919, Inatomi (1920), Yataka (1920), Akiya (1920), Masuda (1922), Shioda (1924), Matsumoto (1925), and Kitabori (1927); these are all recorded in Japanese literature and none was included by Morax in his bibliography. Shoji does not refer to the work of Morax, by far the most complete work on malignant disease of the visual apparatus that has yet appeared.

Addition of these cases to those enumerated by Morax shows that the number of Meibomian cancers communicated to date is 48 .

Diacicov, in his thesis (Cluj Roumanie, 1927), entitled "Statistical research on ocular cancer" found an average of $\mathbf{1 . 4 7}$ per cent. ocular carcinoma among the admissions at the Cluj Clinic, among which was one case of Meibomian localization.

Meibomian cancer is met with more frequently than cancer of the glands of Zeis. It usually occurs in people of middle age, but cases have been recorded at the age of 35 years by Inatomi, 
and at the age of 11 years by Allaire (1891). It affects both sexes and involves the glands of the upper lid more frequently than those of the lower. Its onset is insidious, and it is usually looked upon in the first instance as a chalazion, the free edge of the lid being uninvolved in the early stages. Pain is usually absent, but some patients complain of slight pricking sensations in the region of the tumour. In a more advanced stage the neoplasm involves the neighbouring tissues of the tarsus and the free edge of the lid.

Without histological examination, the diagnosis in the early stages is practically impossible, but a recurrence of a chalazion after surgical intervention should always make us think of the possibility of this condition. Meibomian carcinoma, though of slow evolution, may attain the size of a nut. Some cases grow much more quickly than others.

As the tumour enlarges it gives rise to a false ptosis which narrows the palpebral aperture and may interfere with vision. The skin is usually movable over the tumour, which appears well defined on palpation, encapsulated, tough, elastic and painless.

Meibomian cancer is peculiarly apt to produce metastasis, invading after a while the orbital cavity (Komoto and Shoji). In an advanced case the palpebral conjunctiva is also involved, infiltrated and even ulcerated. Morax cites a case in whom he noticed an adherence of the free edge of the lid to the cornea and to the lower lid. The diagnosis at the start is usually made of a chalazion, or of a syphilitic tarsitis, of vegetant form, when the palpebral conjunctiva is ulcerated.. All authors are agreed that Meibomian neoplasm, by its great tendency to metastasis by the lymphatic paths, is more serious than cancer of the skin of the lid. The prognosis is also complicated by the fact that when the true nature of the tumour has been diagnosed, metastasis has probably already occurred. Histo-pathological examination shows that the tumour, in the first instance, is circumscribed in the lid, giving the appearance of an unusual development of a Meibomian gland. Besides the acini which are of natural size, there are to be found others which are twice as big; these are proliferated acini, separated from each other by a fine fibrous tissue, and vascularized, the vessels passing from the sheath into the tumour. Two kinds of cells can be distinguished, round or elliptical with large nuclei and scanty clear protoplasm, and others with small nuclei and abundant protoplasm. Sebaceous cells sometimes show fatty degeneration and sometimes look like amorphous masses with necrotic nuclei, which stain well with Sudan III.

Treatment must be early and thorough; wide excision of the tumour, followed by autoplasty and extirpation of the tributary 
glands. In advanced cases exenteration of the orbit is indicated, as in the case described by Komoto. Having in view the malignant nature of the tumour surgical treatment should always be followed by radium or Röntgentherapy.

\section{Case History}

C. Gh., $6 \pi$ years of age, came to the clinic at Iassy with a tumour of the free edge of the upper lid of the right eye. The personal and family history were unimportant. The condition started in October, 1928, when a small lump appeared on the outer half of the ciliary border of the lid, of the size of a pin's head, like a grain of hemp; it was circular, clearly subcuticular, and bulged under the conjunctiva. It had grown slowly and without pain and the ciliary edge was a little deformed by some tiny nodes around the main tumour. By 1929 the tumour had increased to the size of a pea and occupied a quarter of the upper lid leaving only a small portion free from growth towards the inner canthus; the malformed ciliary edge formed a spur which deformed the palpebral aperture. In July, 1928, the tumour was operated on by the conjunctival route, but recurred after a few months : in September, 1929, the contents of the little nodes were curetted on the supposition that the condition was a chalazion, but as it would not heal excision of the tumour was recommended to the patient.

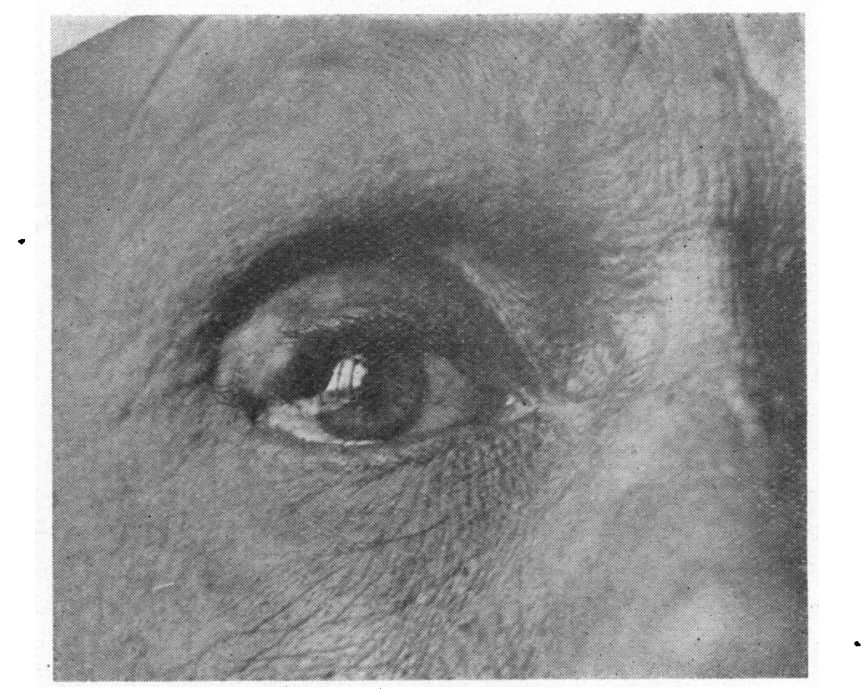

FIG. 1.

Cancer of Meibomian glands 
At this time the upper lid was much deformed, drooping in its outer half, on account of the tumour which was of the size of a pea and appearing to be formed of small nodules crowded together.

The tumour was not painful and the skin was freely movable over it. The outer quarter of the edge of the lid was everted by the tumour; and the sharply angled posterior edge was replaced by a large rounded surface. In this region the lashes were scanty. On the conjunctival surface a series of transparent yellowish stains, placed triangularly, were traceable under the

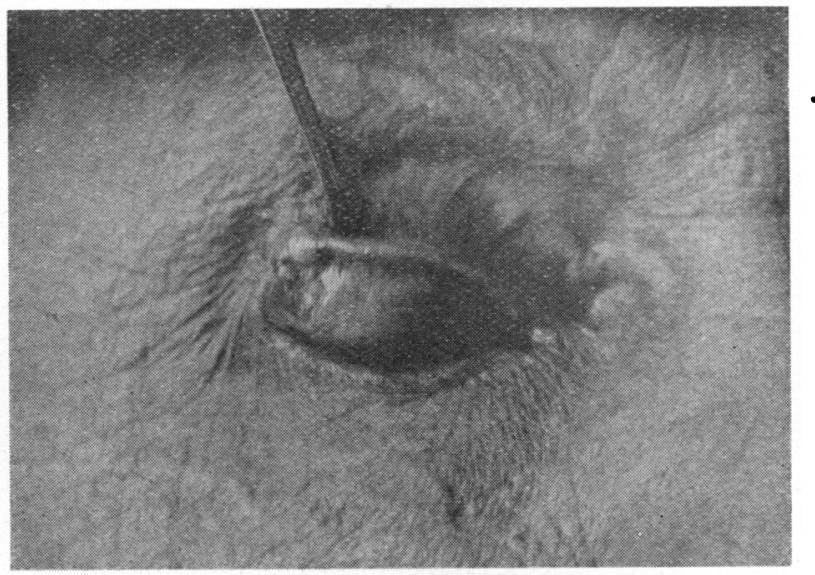

Fig. 2.

The eyelid everted.

nodular lump up to the ciliary edge; these stains were about six in number.

The conjunctival surface was irregular in places, with traces of scar formation; the rest of the conjunctival sac was normal. The eyeball was normal, except for early sclerosis of the lens; the fundus was normal. Reading glasses of $+2 \cdot 25 \mathrm{D}$. $\mathrm{sph}$. were being used.

On February 19, 1930, the tumour was excised by means of a " $V$ " shaped incision, the resulting gap being sutured. The post-operative course was uneventful, the wound healing by first intention.

The tumour was fixed in 10 per cent. formol, embedded in paraffin and in celloidin ; serial sections were cut and stained with haematoxylin, eosine, van Gieson, mucicarmine and Sudan III.

Microscopical examination showed the tumour near the free 
edge of the lid (Fig. 3) the edge of which (Fig. 4) is more involved particularly towards the conjunctival surface. The skin was not invaded. Normal Meibomian acini can be traced towards the base of the eyelid; compared with these acini,

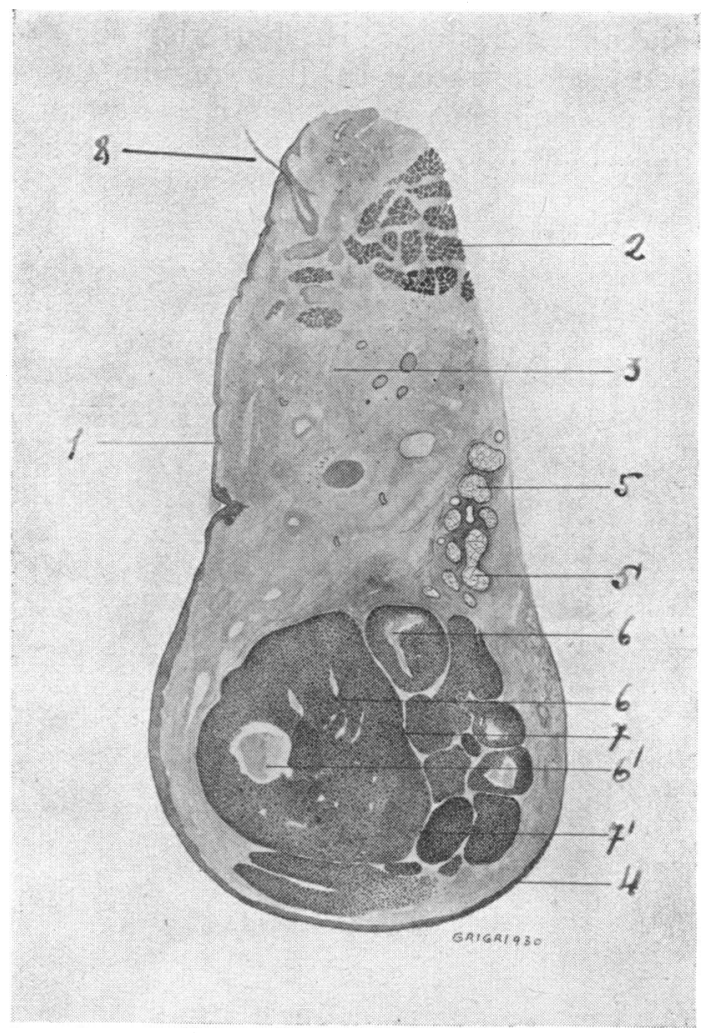

FIG. 3.

Cancer of Meibomian glands (section through the eyelid) : 1 skin; 2 muscle ; 3 tarsus; 4 conjunctiva; 5 and $5^{\prime}$ normal Meibomian acini ; 6 Meibomian cancer; $6^{\prime}$ the region degenerated; 7 and $7^{\prime}$ septum separating the lobules of the tumour; 8 hair follicle.

those of the tumour were 20 to 30 times larger. The tarsus was compressed and the muscle layer thinned. The tumour was formed of approximately six lobuli (Fig. 3). They were separated one from another by thin fibrous septa which carried bluod vessels, which, in places, penetrated into the substance of the growth.

The lobules were surrounded by the neighbouring conjunctival tissue which, on account of the compression, took on a 
capsule-like disposition (Fig. 6). The cells, which have proliferated and have given rise to the growth, were generally vesicular, concentrically arranged, with clear protoplasm and small nuclei; but there were also cells (Fig. 5) with scanty

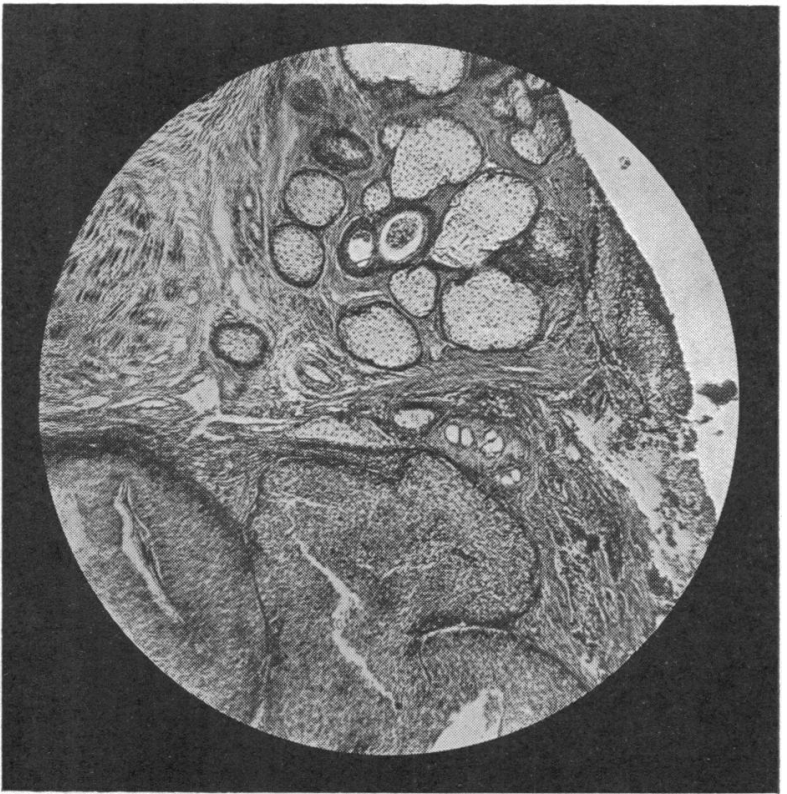

FIG. 4.

Section through the eyelid. As well as the normal glandular acini, the tumour is seen.

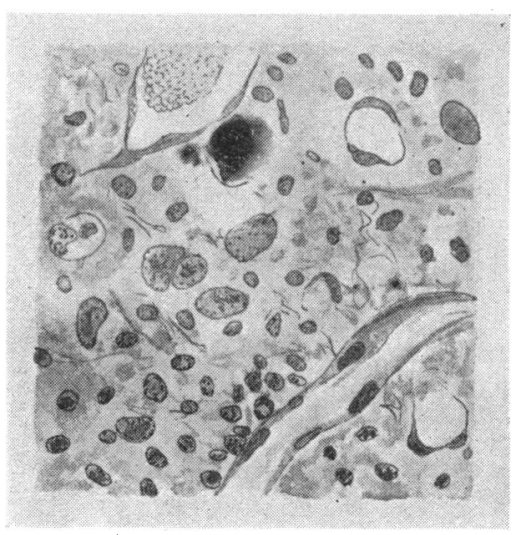

FIG. 5 .

Microscopical detail, showing small cells and large ones. 
protoplasm and larger nuclei, some of which showed kariokinesis. The cells were irregularly placed and crowded together at some points of the growth, and in some places necrosis has occurred, giving rise to vacuolar zones. In the mass of the growth no single Meibomian acinus was seen to be normal. The Sudan III

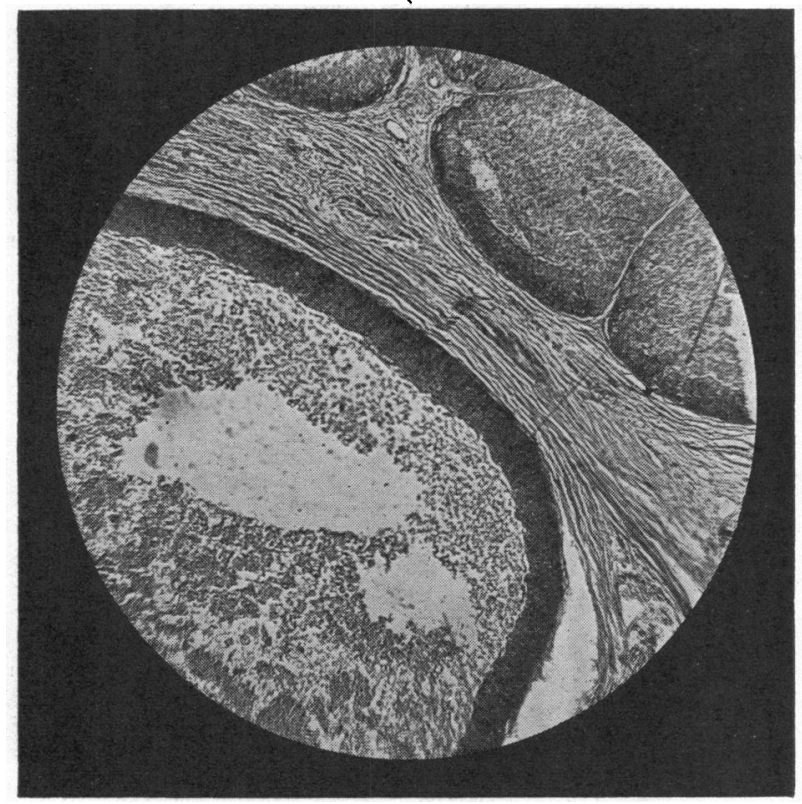

Fig. 6.

The lobules of the tumour are surrounded by the neighbouring conjunctival tissue, which on account of the compression, takes a capsule-like disposition.

stain showed well the Meibomian acini on one side and on the other the Zeis glands situated at the bases of the lash follicles. The tumour was also well stained by Sudan III, but here the staining was more diffuse and not so homogeneous as in the normal glandular acini.

We are obliged to Dr. Mârza for the micro-photographs.

\section{REFERENCES}

1. Glavan, P.-Epiteliom sebaceu al glandelor lui Meibomius. Rev. Sanitara Militarà., N. 6, 7, 1926.

* Morax, V.-Cancer de l'appareil visuel. P. 101, 1926.

3. Pereira (Florence).-Adeno-carcinom palpebral provenant des glandes de Meibomius. Arch. di Ottal., p. 271-275, 1922.

4. Shoji. - Un cas d'épithéliome de la glande de Meibomius, envahissant la cavité orbitaire avec atrophie du globe oculaire. Arch.d'Ophtal.. p. 144, 1929.

- Morax's treatise contains the greater part of the bibliography and Shoji gives the rest, with the cases published in Japanese. 